\title{
AN OPTIMISED QUANTITATIVE REAL-TIME PCR ASSAY FOR LISTERIA MONOCYTOGENES INCLUDING AND INTERNAL AMPLIFICATION CONTROL
}

\author{
$\underline{\text { Rodríguez-Lázaro, D. }}{ }^{{ }^{*}}$, Pla, M. ${ }^{2}$, Scortti, $\mathrm{M}^{1}$, Monzó, H.J. ${ }^{1}$, and Vázquez-Boland, J.A. ${ }^{1}$ \\ ${ }^{1}$ Bacterial Molecular Pathogenesis Group. Faculty of Medical and Veterinary Sciences, \\ University of Bristol, Langford, BS40 5DU, UK. david.rodriguez@bristol.ac.uk \\ ${ }^{2}$ Institute of Food and Agricultural Technology (INTEA). University of Girona, E-17071 \\ Girona, Spain. \\ ${ }^{*}$ To whom correspondence should be addressed.
}

\begin{abstract}
The assessment of results obtained by PCR is a critical issue for its implementation as a routine tool in food microbiology diagnostics. As an analytical technique, PCR is exposed to inhibitors that can produce false negative results or underestimation in quantitative analysis. In this study, we illustrate the design, development and optimization of a duplex real-time PCR (RTi-PCR) assay for the quantitative detection of Listeria monocytogenes based on the co-amplification of a $L$. monocytogenes-specific gene $(h l y)$ sequence (Rodríguez-Lázaro et al., 2004a) and an internal amplification control (IAC) to evaluate PCR performance. A PCR IAC is a non-target DNA that is co-amplified with the same set of primers that target sequence. The assay was $100 \%$ specific as it allowed unambiguously detection of $49 \mathrm{~L}$. monocytogenes isolates of different serotypes and sources and 104 strains of other species were negative. The detection and quantification limits were 8 and 30 cfu respectively, and PCR linearity and efficiency were $\mathrm{R}^{2}=0.997$ and 0.80 respectively. Interestingly, the assay was capable of detecting underestimation of L. monocytogenes in reactions containing inhibitory culture media (e.g. Fraser and Half Fraser media) and foodstuffs (e.g. raw salmon or raw pork meat). Specific L. monocytogenes detection could also be performed using agargrown colonies and by conventional PCR. In conclusion, we present a simple and rapid duplex RTi-PCR assay for the quantitative detection of $L$. monocytogenes, which can also assess potential underestimations or false negative results.
\end{abstract}

\section{KEYWORDS}

Quantitative detection; Real-time PCR; Internal Amplification Control; Listeria monocytogenes.

\section{INTRODUCTION}

Listeria monocytogenes is a human pathogen that can produce a severe disease often associated with the ingestion of contaminated ready-to-eat products (Kathariou, 2000; 2002; Ryser, 1999; Vázquez-Boland et al., 2001). Consequently, the application of microbiological control within the quality assessment programs in the food industry is a premise to minimize the risk of infection with this pathogen for the consumer. In this scenario, the current methodological approach is based on traditional microbiological methods, which are labourintensive and time consuming and produce presumptive results that require additional biochemical tests for the definitive confirmation of this pathogen (Donnelly, 1999). These 
drawbacks are overcome by real-time PCR (RTi-PCR), a technology that may allow the rapid and quantitative detection of infectious agents with extremely high specificity and high sensitivity (Klein, 2002; Mackay, 2004; Rijpens and Herman, 2002; Walker, 2002). Furthermore, the absence of post-PCR analytical steps reduces cross-contamination risks and allows high throughput and automation (Klein, 2002; Mackay, 2004). However, many components of food products, culture media and nucleic acids extraction reagents can act as PCR inhibitors (Rådström et al., 2003; Rossen et al., 1992; Wilson, 1997), and their presence in the reaction may cause a dramatic decrease in sensitivity or even block amplification reaction, consequently generating false negative results or an underestimation of the bacterial load (Hill, 1996; Scheu et al., 1998; Rådström et al., 2003). Therefore, the assessment of the PCR efficiency in every assay is a critical issue for the implementation of PCR as a routinely analytical tool in food microbiology diagnostics. An important analytical control for use with molecular amplification-based methods is the inclusion, in each reaction, of an internal amplification control (IAC) (Hoorfar et al, 2003; Rodríguez Lázaro et al., 2004b). A PCR IAC is a non-target DNA which is co-amplified simultaneously with the target sequence (Ballagi-Pordány and Belák, 1996; Cone et al., 1992;), thus, with negative results for the PCR target, the absence of a positive IAC signal indicates that amplification has failed (Hoorfar et al., 2004). A standard IAC for RTi-PCR assays should include the sequences of the primers for the target sequence flanking an internal region totally unrelated where a fluorescence probe for the IAC detection should be directed. Thus, The simultaneous use in a single reaction of two differently labelled fluorescent probes (for the target and IAC) allows both the detection of the target and assessment of the PCR efficiency in every reaction. Although a number of RTi-PCR assays have been developed for food-borne pathogens detection, adequate IAC have rarely been optimized and never used with quantitative purposes, even when the current consensus among the scientific community is that an IAC should be mandatory for PCR-based diagnostic tests (Hoorfar et al., 2003). Here, we report the development and optimization of a duplex RTi-PCR assay for the specific quantitative detection of L. monocytogenes, which includes an IAC designed to evaluate the PCR performance of every reaction. This assay combines the L. monocytogenes-specific hly-based assay and the amplification of a chimeric IAC DNA. We discuss technical aspects that were critical for optimization of the duplex reaction and provide data of experiments to determine the inhibitory effect of some food products and different culture broths for L. monocytogenes quantitative detection by RTi-PCR.

\section{MATERIAL AND METHODS}

Bacterial strains, grown conditions, DNA isolation and quantification. In this study, the stains (100 Listeria strains -49 L. monocytogenes, 17 L. innocua, 7 L. grayi, 10 L. seeligeri, 5 L. welshimeri and 12 L. ivanovii isolates- and 45 non-Listeria species), growth conditions, DNA isolation and quantification reported in a previous study (Rodríguez-Lázaro et al., 2004a) were used.

IAC preparation. The IAC DNA consisted of a $104 \mathrm{bp}$ fragment of the acetyl-coenzyme A carboxylase gene (GenBank acc. no. X77576) from rapeseed (Brassica napus) flanked by $h l y Q F / R$ primers (Rodríguez-Lázaro et al., 2004a). This chimerical IAC DNA was constructed by a two-step PCR as previously described (Figure 1). Briefly, $100 \mathrm{ng}$ of Brassica napus DNA were amplified using primers hlyccAF (5' catggcaccaccagcatctggtgagctgtataatc 3') and hlyccAR (5' atccgcgtgtttctttcgaggcgcagcatc 3') 
using conditions previously described (Hoorfar et al., 2000). The amplicon was subsequently diluted 1:1,000 in double-distilled water and used as template in a second PCR reaction performed with the $h l y$-specific primers $h l y Q F / R$ in the same conditions. The PCR product was purified using the QIAEX ${ }^{\circledR} \mathrm{II}$ Gel Extraction kit (Qiagen) according to the recommendations of the manufacturer. The eluate was quantified and diluted in doubledistilled water in the presence of $5 \mathrm{ng} / \mu \mathrm{l}$ RNA down to the working concentration.

\section{Figure 1:}

A

Non-target genomic DNA (Brassica nopus)

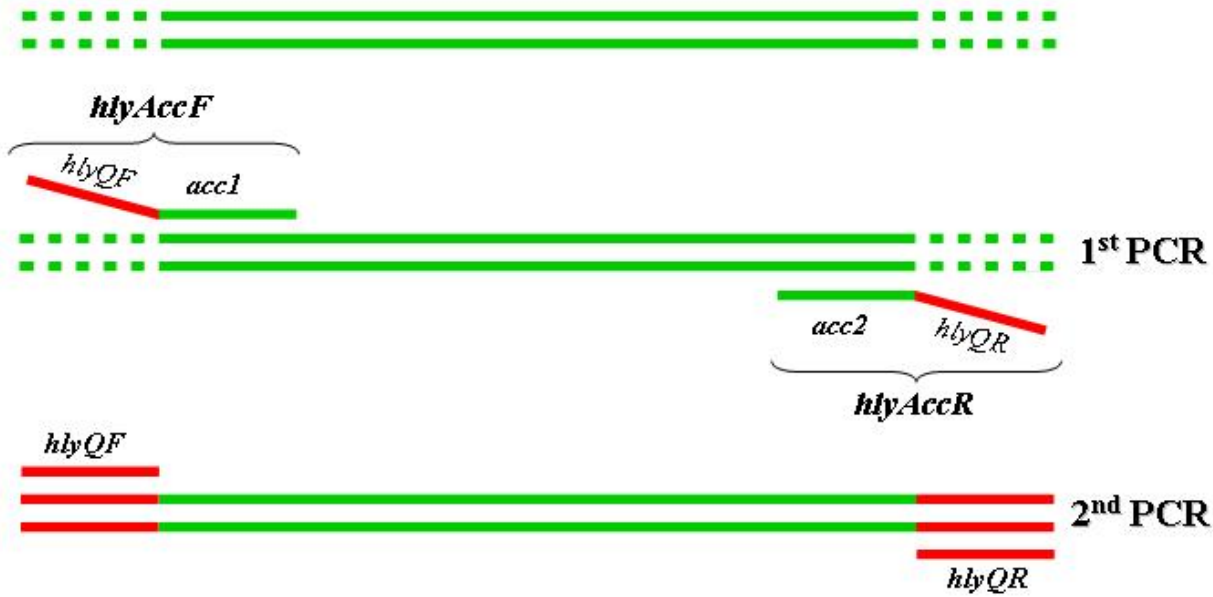

Chimeric LAC DNA

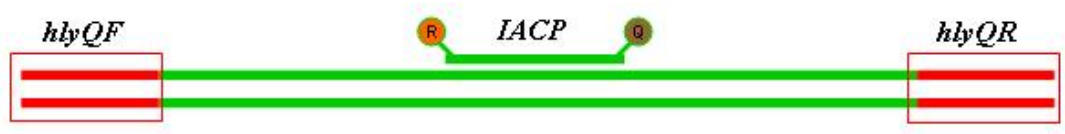

L. monocytogenes DNA

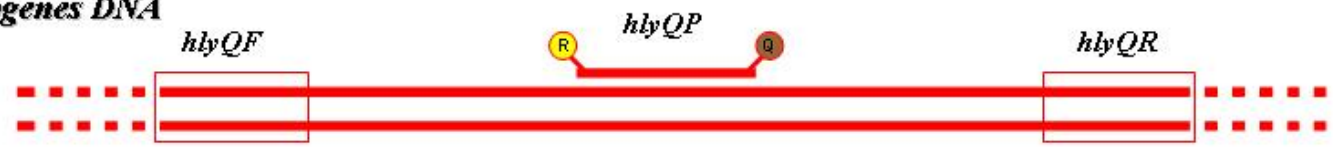

Fig. 1. Schematic representation of the construction of the IAC (A) and of the templates and hybridizing sites for the fluorescent probes in the duplex $h l y$-IAC RTi-PCR (B). In (A), accl and acc2 refer to the 3' B. napus BnACCg8 gene-specific primer sequences.

RTi-PCR. Reactions were performed using TaqMan ${ }^{\circledR}$ PCR core reagents kit (Applied Biosystems-Roche) in a $20 \mu$ reaction volume containing $1 \times$ PCR TaqMan $^{\circledR}$ buffer A (including ROX as a passive reference dye), $6 \mathrm{mM}$ of $\mathrm{MgCl}_{2}, 200 \mu \mathrm{M}$ of each dATP, dCTP, dGTP, 400 of $\mu \mathrm{M}$ dUTP, $50 \mathrm{nM}$ of $h l y Q \mathrm{~F} / R$ primers, $100 \mathrm{nM}$ of $h l y Q P$ probe (FAM and TAMRA double labelled hly-specific probe) [(Rodríguez-Lázaro et al., 2004a) and $100 \mathrm{nM}$ of accp (VIC and and TAMRA double labelled IAC-specific probe) (Hernández et al., 2001), 1 unit of AmpliTaq Gold ${ }^{\circledR}$ DNA polymerase, 0.2 units of AmpErase ${ }^{\circledR}$ uracil $N$ glycosylase (UNG), 100 molecules of IAC DNA (unless specifically stated) and $1 \mu 1$ of the target DNA solution. Reactions were run and analysed as described in Rodríguez-Lázaro et al. (2004a). Conventional (c-)PCR were performed in the same conditions as RTi-PCR 
except for PCR buffer II. PCR products were detected in analytical 3\% agarose gels stained with ethidium bromide.

\section{RESULTS AND DISCUSSION}

Design and construction of the IAC and Optimization of the RTi-PCR assay. The IAC was constructed following the indications shown in the materials and methods. It did not exhibit significant homology to any DNA sequence deposited in DNA databases (different to BnACCg8 positions 9651-9755) when analyzed using the bioinformatics tool BLAST-N. It should be amplified using the $h l y$-specific primers (Rodríguez-Lázaro et al., 2004a) as shows their sequence at 5'- and 3'- ends, respectively, whereas it should not be detected by the hlyspecific probe (FAM-labelled) but with the specific-IAC probe (Hernández et al., 2001) (VIC-labelled). This should facilitate simultaneous detection of L. monocytogenes and IAC in a single reaction by means of each of specific fluorescent probes. In addition, the IAC length is 143-bp, 79-bp longer than the hly-specific amplicon (64-bp), and thus it is also possible to distinguish both amplicon by gel-electrophoresis using c-PCR. In conclusion, we constructed an IAC DNA that did nor reveal homology to any other DNA sequence found in nature (to avoid any cross-reaction) and longer than the $h l y$-specific amplicon (suitable for gel-electrophoresis analysis), and thus fulfilling the sequence and the size recommendations previously described (Ballagi-Pordány and Belák, 1996; Hoorfar et al., 2004).

Subsequently, we optimised the IAC ( $a c c p$ ) probe concentration using decreasing accp probe concentrations (from 250 to $25 \mathrm{nM}$ ) in the conditions previously described for the hly-specific assay (Rodríguez-Lázaro, 2004a) with 1,000 IAC molecules and in the absence of L. monocytogenes DNA, and selecting the minimum probe concentration that did not result in a $\mathrm{C}_{\mathrm{T}}$ increment (i.e. high sensitivity) (Applied Biosystems, 1998; RodríguezLázaro et al., 2004c). Optimal conditions are those described in Materials and Methods. The determination of the optimal concentration of IAC in the PCR assay is a critical step. The IAC concentration should be should be kept as low as possible to avoid negative effect or even inhibition of the target-specific reaction. However, the IAC concentration should not be so low as to make it difficult to obtain reproducible IAC amplification signal. Thus, we determined the detection limit of the IAC using decreasing concentrations of IAC (1000, $300,100,30$ and 10 molecules per reaction) in the absence of L. monocytogenes DNA. The IAC could be consistently detected to 10 molecules, but $\mathrm{VIC} \mathrm{C}_{\mathrm{T}}$ values varied among replicates. In parallel, we also evaluated the IAC inhibition capacity, using reactions that contained increasing amounts of $\operatorname{IAC}(10,30,100,300,1,000$, and 10,000) and approximately $30 \mathrm{~L}$. monocytogenes cells. We observed that $100 \mathrm{IAC}$ molecules was the highest amount of IAC that did not inhibit the L. monocytogenes signal. Considering these results and that we reproducibly detected always 100 IAC molecules by c-PCR (not shown), we established this amount as the IAC concentration per reaction. This number is within the range recommended by Ballagi-Pordány and Belák (50-500 copies) (Ballagi-Pordány and Belák, 1996), and is similar to those used in some previously PCR methods, e.g. 300 (Malorny et al., 2003) or 1,000 (Lambertz et al., 2000) and smaller than those described in other real-time PCR detection assays (Hoorfar et al., 2000; Klerks et al., 2004).

Specificity and sensitivity of the duplex RTi-PCR assay. The specificity of the assay was evaluated using $1 \mathrm{ng}$ of genomic DNA purified from 49 L. monocytogenes strains (including representative strains of the different serovars) and 96 non-target bacteria (51 Listeria strains -17 L. innocua, 7 L. grayi, 10 L. seeligeri, 5 L. welshimeri and 12 L. ivanovii- and 45 non- 
Listeria strains) (see table 1 and 2 of Rodríguez-Lázaro et al., 2004a). In addition, a colony of each strain directly transferred from an agar plate was also tested. The duplex RTi-PCR assay unequivocally distinguished L. monocytogenes isolates, accordingly with previously reported data for $h l y$-specific RTi-PCR assays targeting the same (Rodríguez-Lázaro et al., 2004a) or neighbouring sequences (Nogva et al., 2000; Hough et al., 2002). In addition, all duplex reactions showed a positive (VIC) IAC signal, indicating thus that the negative (FAM) $h l y$-signal obtained from non-L. monocytogenes isolates was not caused by RTi-PCR inhibition.

The L. monocytogenes-specific signal should not be inhibited by the simultaneous coamplification of IAC, especially when small amounts of target molecules are expected. This is of particular relevance for L. monocytogenes, which is often present in low numbers (Ryser et al., 1999). We determined the sensitivity of the duplex RTi-PCR assay in the presence of 100 molecules of IAC using decreasing amounts of genomic DNA from $L$. monocytogenes $\mathrm{UdG} 1010$ (equivalent to approximately 30, 15, 8, 4 and 1 cells). Table 1 shows FAM ( $h l y)$ and VIC (IAC) $\mathrm{C}_{\mathrm{T}}$ and $\Delta \mathrm{R}_{\mathrm{n}}$ values obtained in a total of 9 replicates performed in 3 independent experiments. The duplex RTi-PCR assay consistently detect down to $8 \mathrm{~L}$. monocytogenes DNA molecules and detected at least in a $44.44 \%$ of the replicates corresponding to 4 and 1 target molecules. These results were the same that as the $h l y$-specific assay (Rodríguez-Lázaro et al., 2004a), and similar to other $h l y$-specific RTiPCR assays (Hough 20002; Nogva et al., 2000). As expected, co-amplification of IAC was positive in all reactions, with overall $C_{T}$ values of $33.59 \pm 0.68$ and $\Delta R_{n}$ values of $0.66 \pm$ 0.11 . The sensitivity of the duplex c-PCR assay was evaluated using the same experimental design. We consistently detected down to 15 target molecules, i.e. the sensitivity was slightly poorer in c-PCR than in RTi-PCR assays (data not shown). In conclusion, addition of 100 initial IAC molecules did not result in any detectable decrease in the sensitivity of the assay.

Table 1. Detection and quantification limits of the duplex RTi-PCR assay. 100 IAC molecules were included in each reaction. Lower and upper limit confidence intervals were calculated for the expected template molecules in each dilution at $95 \%$ confidence level. $\mathrm{C}_{\mathrm{T}}$ is the cycle number at which the fluorescence intensity equals a fixed threshold and $\Delta \mathrm{R}_{\mathrm{n}}$ represents the $R_{n}^{+}$(reporter emission intensity/passive reference emission intensity) compared to $R_{n}^{-}$(background reporter emission intensity/passive reference emission intensity calculated in no template controls-) (Applied Biosystems, 1998).

\begin{tabular}{|c|c|c|c|c|c|c|c|c|c|c|c|}
\hline \multirow{3}{*}{$\begin{array}{l}\text { Approx. no } \\
\text { L. monocytogenes } \\
s \text { molecules }\end{array}$} & \multirow{2}{*}{\multicolumn{2}{|c|}{$\begin{array}{c}\text { Confidence interval } \\
\text { limit }^{\mathrm{a}}\end{array}$}} & \multirow{3}{*}{$\begin{array}{l}\text { Signal ratio } \\
\text { (positive signal } \\
\text { /9 reactions) }\end{array}$} & \multicolumn{4}{|c|}{ hly system (FAM) } & \multicolumn{4}{|c|}{ IAC system (VIC) } \\
\hline & & & & \multicolumn{2}{|c|}{$\mathrm{C}_{\mathrm{T}}^{\mathrm{b}}$} & \multicolumn{2}{|c|}{$\Delta \mathrm{R}_{\mathrm{n}}$} & \multicolumn{2}{|c|}{$\mathrm{C}_{\mathrm{T}}^{\mathrm{c}}$} & \multicolumn{2}{|c|}{$\Delta \mathrm{R}_{\mathrm{n}}$} \\
\hline & Lower & Upper & & Mean & SD & Mean & SD & Mean & SD & Mean & SD \\
\hline $3 \times 10^{4}$ & 29661 & 30340 & 9 & 22.38 & 0.11 & 0.98 & 0.03 & 33.67 & 0.79 & 0.10 & 0.01 \\
\hline $3 \times 10^{3}$ & 2893 & 3108 & 9 & 25.91 & 0.10 & 0.92 & 0.09 & 33.56 & 0.75 & 0.12 & 0.03 \\
\hline $3 \times 10^{2}$ & 267 & 334 & 9 & 30.17 & 0.15 & 0.91 & 0.02 & 33.67 & 0.57 & 0.26 & 0.04 \\
\hline 60 & 45 & 76 & 9 & 32.49 & 0.19 & 0.81 & 0.02 & 33.14 & 0.47 & 0.43 & 0.04 \\
\hline 30 & 20 & 41 & 9 & 34.25 & 0.16 & 0.78 & 0.04 & 33.57 & 0.66 & 0.53 & 0.06 \\
\hline 15 & 8 & 23 & 9 & 35.57 & 0.57 & 0.75 & 0.06 & 33.76 & 0.74 & 0.65 & 0.10 \\
\hline 8 & 3 & 13 & 9 & 36.07 & 0.59 & 0.73 & 0.02 & 33.54 & 0.47 & 0.70 & 0.06 \\
\hline 4 & 1 & 8 & 5 & $35.58^{\mathrm{d}}$ & $0.76^{\mathrm{d}}$ & $0.79^{d}$ & $0.05^{\mathrm{d}}$ & $33.36^{\mathrm{d}}$ & $0.31^{\mathrm{d}}$ & $0.73^{\mathrm{d}}$ & $0.09^{\mathrm{d}}$ \\
\hline 1 & 0 & 3 & 4 & $35.56^{\mathrm{d}}$ & $1.03^{\mathrm{d}}$ & $0.85^{\mathrm{d}}$ & $0.06^{\mathrm{d}}$ & $33.71^{\mathrm{d}}$ & $0.75^{\mathrm{d}}$ & $0.70^{\mathrm{d}}$ & $0.11^{\mathrm{d}}$ \\
\hline
\end{tabular}

${ }^{\mathrm{a}}$ Calculated for the expected number of template molecules at each dilution at the $95 \%$ confidence level

${ }^{\mathrm{b}} \mathrm{FAM} \mathrm{C}_{\mathrm{T}}$ values were calculated with a prefixed threshold at 0.035 , and a baseline from cycles 3 to 15 .

${ }^{\mathrm{c}} \mathrm{VIC} \mathrm{C}_{\mathrm{T}}$ values were calculated with a prefixed threshold at 0.035 , and a baseline from cycles 3 to 23 .

${ }^{\mathrm{d}}$ hly negative amplifications were excluded from Mean and SD calculations.

Quantification capacity of $L$. monocytogenes by duplex RTi-PCR assay. We assessed the suitability of the developed duplex RTi-PCR assay to accurately quantify $L$. monocytogenes using decreasing amounts of $L$. monocytogenes strain UdG 1010 genomic DNA (equivalent to $3 \times 10^{4}, 3 \times 10^{3}, 3 \times 10^{2}, 60$ and 30 target DNA molecules per reaction). Table 1 shows FAM (hly) and VIC (IAC) $\mathrm{C}_{\mathrm{T}}$ and $\Delta \mathrm{R}_{\mathrm{n}}$ values from a total of 9 replicates of 3 independent experiments. As expected, there was an excellent linearity between initial L. monocytogenes 
DNA molecules and FAM $\mathrm{C}_{\mathrm{T}}$ values down to 30 target molecules, as indicated by the square regression coefficient $\left(\mathrm{R}^{2}=0.997\right)$. This, together with the small SD obtained in the replicates and in independent experiments, indicated that quantification of L. monocytogenes can be achieved by the developed duplex RTi-PCR assay. The quantification limit of the duplex assay, further confirmed by theoretical statistical analyses, can be established at 30 cells, the same as that previously reported for the corresponding uniplex assay (RodríguezLázaro et al., 2004a) and similar to most of the quantitative RTi-PCR systems published to date (e.g. Bach et al., 2003; Hernández et al., 2003).

The PCR amplification efficiency can be calculated through the equation $E=10^{-1 / s}-1$, where $s$ is the slope of the linear regression curve (Klein et al., 1999). When the efficiency is optimal (1.00), the slope is -3.322 (Knutsson et al., 2002). The slope of the duplex PCR assay (-3.916) denoted a 0.800 efficiency, slightly below the efficiency of the corresponding hly assay (0.916) which signifies an $87.38 \%$ of the uniplex PCR efficiency. Comparison of $h l y$ and IAC amplification profiles (Table1) evidenced that the $h l y$-specific reaction predominates above that for IAC. hly (FAM) $\Delta \mathrm{R}_{\mathrm{n}}$ values were above 0.74 in all reactions (overall, $\Delta \mathrm{R}_{\mathrm{n}} 0.84 \pm 0.09$ ), whereas IAC (VIC) $\Delta \mathrm{R}_{\mathrm{n}}$ values gradually decreased from 0.73 in reactions containing $4 \mathrm{~L}$. monocytogenes DNA molecules down to 0.10 when $30,000 \mathrm{~L}$. monocytogenes DNA molecules were added to the reaction. This was in contrast with VIC $\mathrm{C}_{\mathrm{T}}$ values that, as expected, were highly stable (overall $\mathrm{C}_{\mathrm{T}}$ value $=33.56 \pm 0.69$ ).

Use of the duplex RTi-PCR assay for the quantitative detection of $L$. monocytogenes in the presence of different culture broths. We tested the applicability of our duplex RTiPCR assay to quantitative detect L. monocytogenes in the presence of four different culture media typically used for the microbiological detection or quantification of this species: Fraser, half-Fraser, BHI and buffered peptone water. We performed duplex RTi-PCR using as template 300 copies of genomic DNA from L. monocytogenes strain UdG 1010 and 100 molecules of IAC, and adding to the PCR mix $1 \mu \mathrm{l}$ of either media or double-distilled water (as control). Both FAM and VIC $\mathrm{C}_{\mathrm{T}}$ values obtained in the presence of BHI broth, buffered peptone water or double-distilled water were not statistically different $(\mathrm{p}<0.05)$. Based on FAM values, $283 \pm 25$ L. monocytogenes DNA molecules were calculated in each sample, which corresponded to $94.00 \pm 8.00 \%$ of the real value. VIC $\mathrm{C}_{\mathrm{T}}$ values proved the lack of inhibition due to BHI and particularly, buffered peptone water, specified for use in the $L$. monocytogenes enumeration standard (Anonymous, 1998). In contrast, reactions containing Fraser or half-Fraser media (specified for use in the L. monocytogenes detection standard, Anonymous, 1996) showed $h l y$ and IAC positive amplification, although with significantly higher FAM and VIC $\mathrm{C}_{\mathrm{T}}$ values (above 40 i.e. below the quantification limit). This confirmed that these media act as a potent PCR inhibitors. Several of its components e.g. $\mathrm{LiCl}$, nalidixic acid, acriflavin and exculin have also been shown to inhibit PCR (Rossen et al., 1992).

Quantitative detection of $L$. monocytogenes by the duplex assay in different foods and assessment of the PCR results by the IAC. We also assessed the applicability of the duplex RTi-PCR assay for the quantification of L. monocytogenes in different food matrixes typically contaminated by this pathogen: meat and meat products (raw pork meat, pork fermented sausage, frankfurter sausage and pork cook ham) and fish and fish products (raw salmon and cold-smoked salmon). These food matrices were artificially contaminated with decreasing concentrations of of L. monocytogenes strain UdG 1010 (approximately from $3 \times 10^{7}, 3 \times 10^{6}$ and $3 \times 10^{5} \mathrm{cfu} / \mathrm{g}$ ), and $1 \mu \mathrm{l}$ of a $1: 10$ dilution $(\mathrm{w} / \mathrm{v})$ of the homogenate in buffered peptone water was directly used for the duplex RTi-PCR assay. In parallel, the 
standard microbiological procedure (Anonymous, 1998) was performed to ensure that the lack of amplification was not caused by the absence of L. monocytogenes cells in the food sample. The results obtained from the meat products (pork fermented sausage, frankfurter sausage and pork cook ham) showed an adequate amplification signals for L. monocytogenes both considering each food sample separately and considering the results globally (Table 2). These results indicate that the quantitative detection of $L$. monocytogenes in meat products is achievable since the FAM $\mathrm{C}_{\mathrm{T}}$ results obtained were not statistically different $(\mathrm{p}<0.05)$ to those obtained from purified DNA solutions (see Tables 1 and 2). In addition, it was observed non-statistically different results for IAC $(\mathrm{p}<0.05)$ to those previously obtained for DNA solutions (overall VIC $C_{T}$ values of $33.64 \pm 0.57$ ). However, when raw food materials (pork meat and salmon) and cold-smoked salmon were assayed, it was observed a lack of $L$. monocytogenes (FAM) amplification signal in all the cases. In addition, no IAC (VIC) amplification signal was obtained either, indicating that the failure in detecting $L$. monocytogenes was due to inhibition of the duplex RTi-PCR assay in these particular food matrixes. This finding emphasizes the importance of including an IAC as it provides a consistent tool to distinguish between real and false negative results.

TABLE 2. Detection of L. monocytogenes by RTi-PCR assay in different food matrices.

\begin{tabular}{cccccccccc}
\hline \begin{tabular}{c} 
Approx. no. of $\begin{array}{c}\text { Approx. no. of } \\
\text { L. } \\
\text { monocytogenes } \\
\text { cfu/g }\end{array}$ \\
\cline { 3 - 10 }
\end{tabular} & $\begin{array}{c}\text { Lonocytogenes } \\
\text { cfu/reaction }\end{array}$ & $\begin{array}{c}\text { pork } \\
\text { fermented } \\
\text { sausage }\end{array}$ & $\begin{array}{c}\text { Frankfurter } \\
\text { sausage }\end{array}$ & $\begin{array}{c}\text { Pork cook } \\
\text { ham }\end{array}$ & overall \\
\cline { 3 - 10 } & & Mean & SD & Mean & SD & Mean & SD & Mean & SD \\
\hline $3 \times 10^{7}$ & $3 \times 10^{3}$ & 26.05 & 0.30 & 25.94 & 0.23 & 26.05 & 0.30 & 26.00 & 0.27 \\
$3 \times 10^{6}$ & $3 \times 10^{2}$ & 29.26 & 0.31 & 29.68 & 0.37 & 29.43 & 0.17 & 29.46 & 0.39 \\
$3 \times 10^{5}$ & $3 \times 10^{1}$ & 33.01 & 0.62 & 29.43 & 0.59 & 32.49 & 0.57 & 32.81 & 0.65 \\
\hline
\end{tabular}

${ }^{\mathrm{a}} \mathrm{FAM} \mathrm{C} \mathrm{C}_{\mathrm{T}}$ values were calculated with a prefixed threshold at 0.035 , and a baseline from cycles 3 to 15 .

In conclusion, we have further developed and optimised a previously reported RTi-PCR assay for quantitative detection of L. monocytogenes (Rodríguez-Lázaro et al., 2004a) with the inclusion of an IAC. This improved duplex RTi-PCR assay maintains the same specificity, sensitivity and quantification ability characteristics of the original assay whilst providing the capacity to identify false negative results or target underestimation due to the presence of PCR inhibitors in the samples and can be also applied in the sensitive detection of PCR inhibitors in the samples. Finally, using artificially contaminated food matrixes, we provided direct evidence that the duplex assay can be a consistent alternative tool for the routine quantitative detection of $L$. monocytogenes in food products.

\section{ACKNOWLEDGEMENTS}

We thank Marta Hugas and Nigel Cook for providing bacterial strains. This work was supported by the Spanish Ministerio de Ciencia y Tecnología grant AGL2002-03496. D.R.-L. was supported by fellowships from Universitat de Girona and the Leverhulme Trust. D.R.-L. is a research fellow of the European Union's MarieCurie mobility program.

\section{REFERENCES}

1. Anonymous (1998) ISO 11290-2: 1998: Microbiology of food and animal feeding stuffs - Horizontal method for the detection and enumeration of Listeria monocytogenes - Part 2: Enumeration method. Geneva: International Organization for Standardization. 
2. Anonymous (1996) ISO 11290-1: 1996: Microbiology of food and animal feeding stuffs - Horizontal method for the detection and enumeration of Listeria monocytogenes - Part 1: Detection method. Geneva: International Organization for Standardization.

3. Applied Biosystems (1998) User Bulletin \#5, ABI Prism 7700 SDS.

4. Bach, H.J., Jessen, I., Schloter, M. and Munch, J.C. (2003) A TaqMan-PCR protocol for quantification and differentiation of the phytopathogenic Clavibacter michiganensis subspecies. J. Microbiol. Methods 52, 85-91.

5. Ballagi-Pordány, A. and Belák, S. (1996) The use of mimics as internal standards to avoid false negatives in diagnostic PCR. Mol. Cell. Probes 10, 159-164.

6. Cone, R.W., Hobson, A.C. and Huang, M.L. (1992) Co-amplified positive control detects inhibition of polymerase chain reactions. J. Clin. Microbiol. 30, 3185-3189.

7. Donnelly, C.W. (1999) Conventional methods to detect and isolate Listeria monocytogenes. In: Listeria, Listeriosis, and Food Safety, $2^{\text {nd }}$ ed. (Ryser E.T. and Marth E.H., Eds). pp. 225-260.Marcel Dekker Inc., New York

8. Hernández, M., Rio, A., Esteve, T., Prat, S. and Pla, M. (2001) A rapeseed-specific gene, acetyl-CoA carboxylase, can be used as a reference for qualitative and real-time quantitative PCR detection of transgenes from mixed food samples. J. Agri. Food Chem. 49, 3622-3627.

9. Hernández, M., Pla, M., Esteve, T., Prat, S., Puigdoménech, P. and Ferrando, A. (2003) A specific realtime quantitative PCR detection system for event MON810 in maize YieldGard based on the 3'-transgene integration sequence. Transgenic Res. 12, 179-189.

10. Hill, W.E. (1996) The polymerase chain reaction: applications for the detection of foodborne pathogens. Crit. Rev. Food Sci. Nutr. 36: 123-173.

11. Hoorfar, J., Ahrens, P. and Rådström, P. (2000) Automated 5' Nuclease PCR Assay for Identification of Salmonella enterica. J. Clin. Microbiol. 38, 3429-3435.

12. Hoorfar, J., Cook, N., Malorny, B. Rådström, P., De Medici, D., Abdulmawjood A. and Fach, P. (2003) Making internal amplification control mandatory for diagnostic PCR. J. Clin. Microbiol. 41, 5835.

13. Hoorfar, J., Malorny, B., Abdulmawjood, A., Cook, N., Wagner, M. and Fach, P (2004) Practical considerations in design of internal amplification control for diagnostic PCR assays. J. Clin. Microbiol. 2004 42: 1863-1868.

14. Hough, A.J., Harbison, S.A., Savill, M.G., Melton, L.D. and Fletcher, G. (2002) Rapid enumeration of Listeria monocytogenes in artificially contaminated cabbage using real-time polymerase chain reaction. J. Food Prot. 65, 1329-1332.

15. Kathariou, S. (2000) Pathogenesis determinants of Listeria monocytogenes. In: Cary, J.W., Linz, J. and Bhatnagar, D. (Eds.) Microbial foodborne diseases: mechanisms of pathogenesis and toxin synthesis. Technomic Publishing co, Inc., Lancaster, USA: pp. 295-314.

16. Kathariou, S. (2002) Listeria monocytogenes virulence and pathogenicity, a food safety perspective. J. Food Prot. 65: 1811-1829.

17. Klein, D. (2002) Quantification using real-time PCR technology: applications and limitations. Trends. Mol. Med. 8: 257-260.

18. Klein, D., Janda, P., Steinborn, R., Muller, M., Salmons, B. and Gunzburg, W.H. (1999) Proviral load determination of different feline immunodeficiency virus isolates using real-time polymerase chain reaction: influence of mismatches on quantification. Electrophoresis 20, 291-299.

19. Lambertz, S.T., Ballagi-Pordány, A. and Lindqvist, R. (1998) A mimic as internal standard to monitor PCR analysis of foodborne pathogens. Lett. Appl. Microbiol. 26, 9-11.

20. Mackay, I.M. 2004. Real-time PCR in the microbiology laboratory. Clinical Microbiology \& Infection. $10,190-212$

21. Malorny, B., Hoorfar, J., Bunge, C. and Helmuth, R. (2003) Multicenter Validation of the Analytical Accuracy of Salmonella PCR: towards an International Standard. Appl. Environ. Microbiol. 69, 290-296.

22. Nogva, H.K., Rudi, K., Naterstad, K., Holck, A. \& Lillehaug, D. (2000) Application of 5'-Nuclease PCR for Quantitative Detection of Listeria monocytogenes in Pure Cultures, Water, Skim Milk, and Unpasteurized Whole Milk. Appl. Env. Microbiol. 66, 4266-4271.

23. Rådström, P., Knutsson, R., Wolfs P., Dahlenborg and Löfström, Ch. (2003) Pre-PCR processing of sampling. In: Sachse, K. and Frey, J. (Eds.) Methods in Molecular Biology: PCR detection of microbial pathogens. Humana Press, Totowa, USA: pp 31-50.

24. Rijpens, N.P. \& Herman, L.M. (2002) Molecular methods for identification and detection of bacterial food pathogens. J. AOAC Int. 85, 984-995.

25. Ryser, E.T. (1999) Foodborne listeriosis. In: Listeria, Listeriosis, and Food Safety, $2^{\text {nd }}$ ed. (Ryser, E.T. and Marth, E.H., Eds.). pp. 299-358. Marcel Dekker Inc., New York. 
26. Rodríguez-Lázaro, D., Hernández, M., Scortti, M., Esteve, T., Vázquez-Boland, J. and Pla, M. (2004a) Quantitative detection of Listeria monocytogenes and Listeria innocua by real-time PCR: assessment of hly, iap and lin02483 targets and AmpliFluor ${ }^{\mathrm{TM}}$ technology. Appl. Environ. Microbiol. 70, 1366-1377.

27. Rodríguez-Lázaro, D., D’Agostino, M., Pla, M. and Cook, N. (2004b) A construction strategy for an internal amplification control (IAC) for molecular beacon-based real-time nucleic acid sequence-based amplification (NASBA). J. Clin. Microbiol. In press.

28. Rodríguez-Lázaro, D., D’Agostino, M. Herrewegh, A., Pla, M., Cook, N. and Ikonomopoulos, J. (2004c) Real-time PCR-based methods for quantitative detection of Mycobacterium avium subsp. paratuberculosis in water and milk. Int. J. Food Microbiol. In press.

29. Rossen, L., Nøskov, P., Holmstrøm, K. and Rasmussen, O.F. (1992) Inhibition of PCR by components of food samples, microbial diagnostic assays and DNA extraction solution. Int. J. Food Microbiol. 17, 37-45.

30. Scheu, P.M., Berghof, K. and Stahl, U. (1998) Detection of pathogenic and spoilage microorganisms in food with the polymerase chain reaction. Food Microbiol. 15: 13-31.

31. Vázquez-Boland, J.A., Kuhn, M., Berche, P., Chakraborty, T., Domínguez-Bernal, G., Goebel, W., González-Zorn, B., Wehland, J. and Kreft, J. (2001) Listeria pathogenesis and molecular virulence determinants. Clin. Microbiol. Rev. 14, 584-640.

32. Walker, N. (2002) A technique whose time has come. Science 296: 557-559.

33. Wilson, I.G. (1997) Inhibition and facilitation of nucleic acid amplification. Appl. Environ. Microbiol. 63: 3741-3751. 